\title{
Correction to: Emotion recognition of speech signal using Taylor series and deep belief network based classification
}

\author{
Arul Valiyavalappil Haridas $^{1,3} \cdot$ Ramalatha Marimuthu $^{2} \cdot$ V. G. Sivakumar ${ }^{3} \cdot$ Basabi Chakraborty $^{4}$
}

Published online: 17 December 2020

c) Springer-Verlag GmbH Germany, part of Springer Nature 2020

Correction to: Evolutionary Intelligence

https://doi.org/10.1007/s12065-019-00333-3

In the online published article, corresponding author has missed to update the following affiliation "Research scholar. Sathyabama Institute of Science and Technology, Chennai, India". The current affiliation is given below. The original article has been corrected.

The original article can be found online at https://doi.org/10.1007/ s12065-019-00333-3.

The original article has been corrected.

\footnotetext{
Arul Valiyavalappil Haridas

arul.vh01@gmail.com

1 ECE, Thejus Engineering College, Thrissur, Kerala, India

2 ECE, Kumaraguru College of Technology, Coimbatore, Tamil Nadu, India

3 Present Address: Sathyabama Institute of Science and Technology, Sathyabama University, Chennai, India

4 Iwate Perfectural University, Takizawa, Japan
} 